\title{
The Significance of Ultrasound Findings in Female Adnexal Tumor of Probable Wolffian Origin (FATW0): Case Review Series
}

\author{
Jiamin Luo, Zhengping Wang* \\ Department of Ultrasound, Women's Hospital, School of Medicine, Zhejiang University, Hangzhou, China \\ Email: *wangzp@zju.edu.cn
}

How to cite this paper: Luo, J.M. and Wang, Z.P. (2020) The Significance of Ultrasound Findings in Female Adnexal Tumor of Probable Wolffian Origin (FATWO): Case Review Series. Open Journal of Obstetrics and Gynecology, 10, 990-999.

https://doi.org/10.4236/ojog.2020.1080094

Received: June 26, 2020

Accepted: August 3, 2020

Published: August 6, 2020

Copyright $\odot 2020$ by author(s) and Scientific Research Publishing Inc. This work is licensed under the Creative Commons Attribution International License (CC BY 4.0).

http://creativecommons.org/licenses/by/4.0/

\begin{abstract}
Background: Kariminejad and Scully reported 9 cases that were difficult to identify outside the ovary Tumors, located in the broad ligament, fallopian tube mesentery, and ovary, named female adnexal tumors of probable Wolffian origin. Aim: To investigate ultrasound images with female adnexal tumors of probable Wolffian origin (FATWOs). Case Report: We reported ultrasound images in three women with female adnexal tumors of probable Wolffian origin (FATWOs) with detailed discussion. Ultrasonography showed a predominantly-solid mass with clear-cut boundary with neighboring normal ovary at the left mesosalpinx (broad ligament) in both cases. Doppler examination presented moderate color content in both tumors. Conclusion: Ultrasound images may provide a clue for preoperative diagnosis of FATWOs.
\end{abstract}

\section{Keywords}

FATWO, Ultrasonography, Female Adnexal Tumors, Wolffian Tumor

\section{Introduction}

Female adnexal tumors of probable Wolffian origin (FATWOs) are rare neoplasms, a rare epithelial tumor that mainly occurs in the pelvic cavity and is located in the broad ligament, fallopian tube mesentery, and ovary. The tumor was originally named FATWOs, mainly because it is similar to the site and morphology of the tumor that originated from the Müllerian duct, so the origin of the tumor cannot be determined. The 2003 of the WHO Breast and Female Reproductive System Classification was officially named as Wolffian adnexal tumor. Less than 90 cases of FATWOs have been reported up to date and all those 
reports are mainly focused on clinicopathologic features. Preoperative diagnosis of FATWOs is pivotal due to their malignant potential, but diagnostic experience is very limited because these tumors lack specific tumor markers and their imaging features are not well documented. Here, we described ultrasound findings in three patients with FATWOs with the aim of contributing to the preoperative diagnosis of FATWOs.

\section{Case Reports}

A 45-year-old woman (Case 1), gravid 3, parity 1, was admitted to our hospital in January 2012 because a pelvic mass was incidentally found by ultrasound in her routine physical check-up. She did not have any complaints. Physical examination had no positive findings. The laboratory assays including biochemistry, heamaetology, tumor markers, and reproductive hormones were all within the normal range.

She underwent laparoscopy and a $4 \times 4 \times 5 \mathrm{~cm}^{3}$ solid mass was found in the left mesosalpinx, at a distal part of the broad ligament between the ovary and fallopian tube. It had a smooth contour and soft cut surface. Bilateral fallopian tubes and ovaries were normal. There were several small endometriotic nodules on the surface of the posterior uterine wall and infundibulopelvic ligament. Sex cord tumor was diagnosed by frozen section. Left salpingo-oophorectomy was performed and tumor was completely removed. The patient was followed up and remained well for 8 years after surgery.

Another 45-year-old woman (Case 2), gravid 3, parity 1, was admitted to our hospital in October 2012 with a 6-year history of pelvic mass and mild lumbago for two months. Physical examination showed uterine enlargement and thickening with pressing pain in the left adnexal region, but no mass was palpable. The biochemical and hematological test, reproductive hormones, and serum tumor markers including CA125, CA199, AFP and CEA, as well as cervical cytology, were not abnormal.

She underwent laparotomy and a solid-cystic mass was found with a diameter of approximately $4 \mathrm{~cm}$ in the left mesosalpinx. The tumor was well demarcated, but partially connected to the ampullar region of the left fallopian. The cut surface of the tumor was light red and soft in the solid part. Bilateral fallopian tubes and ovaries appeared to be normal. The enlarged uterus involved 4 leiomyomas. FATWO was suspected by intraoperative frozen section. The patient underwent left salpingo-oophorectomy and uterine myomectomy. Her clinical course was uneventful. The patient was followed up and remained well for 8 years after surgery.

Recent 27-year-old woman (Case 3), gravid 3, parity 1, was admitted to our hospital in December 2017 with a pelvic mass was incidentally found by ultrasound for two months. Physical examination showed no mass was palpable in uterine and the both adnexal region. The biochemical and hematological test, reproductive hormones, and serum tumor markers, were normal, as well as cervical cytology. 
She underwent laparoscopy and a neoplasm with a $3 \times 3 \times 2 \mathrm{~cm}^{3}$ mass was seen in the mesangium of the ampulla of the right fallopian tube. The surface was smooth, soft, and clear from the surrounding tissue. The cut surface of the tumor was soft. FATWO was suspected by intraoperative frozen section. Right salpingo-oophorectomy was performed and tumor was completely removed. The patient was followed up and remained well for 30 months after surgery.

Transvaginal ultrasonography indicated a well-demarcated ovoid hypoechoic mass, $4.0 \times 4.1 \times 4.8 \mathrm{~cm}^{3}$ in Case 1 (Figure $1(\mathrm{~A})$ ), $4.4 \times 3.8 \times 3.0 \mathrm{~cm}^{3}$ in Case 2 (Figure 1(B)), $2.7 \times 2.0 \times 2.5 \mathrm{~cm}^{3}$ in Case 3 (Figure $1(\mathrm{C})$ ) at the both adnexal region in three cases. The mass was predominantly solid in three cases and with closely packed small cysts in Case 2. CDFI showed moderate color content in the mass (Figures 1(D)-(F)) with the RI of 0.43 in Case 1 and 0.57 in Case 2 and 0.52 in Case 3, respectively. Case 1 and Case 2 tumors appeared to be more closely associated with the left fallopian tube or broad ligament rather than with the left ovary, Case 3 tumors appeared to be more closely associated with the

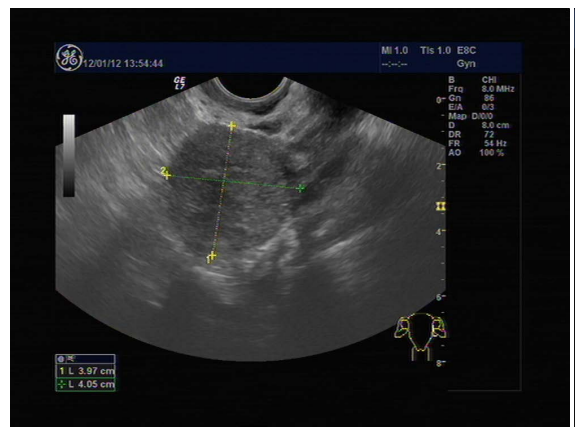

(A)

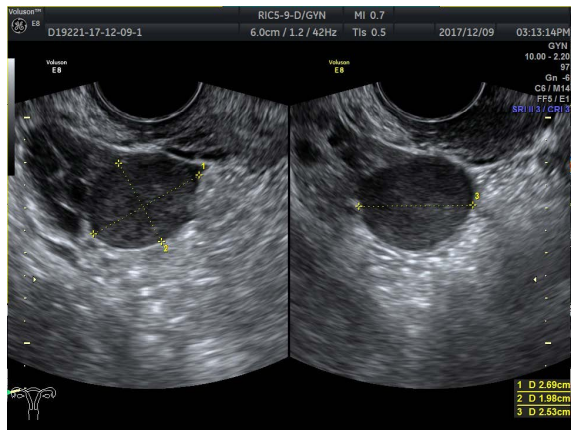

(C)

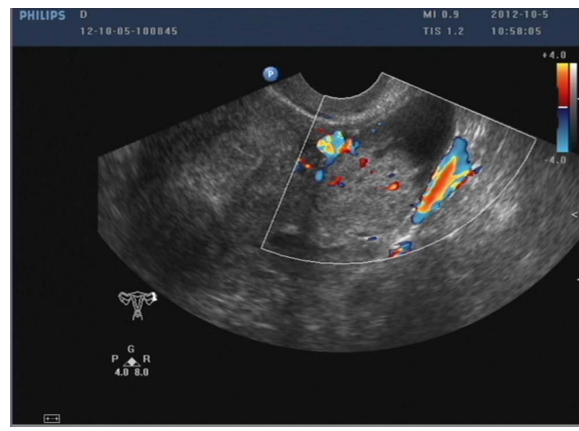

(E)

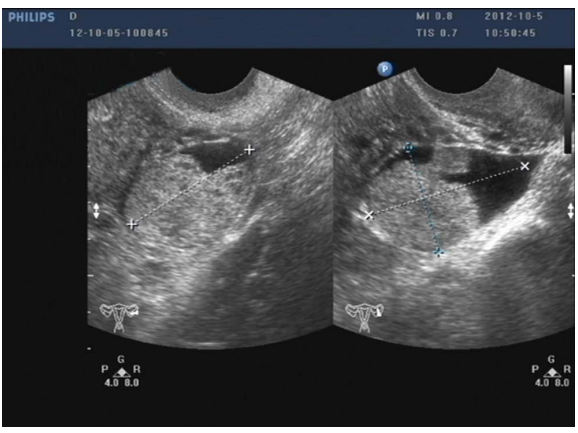

(B)

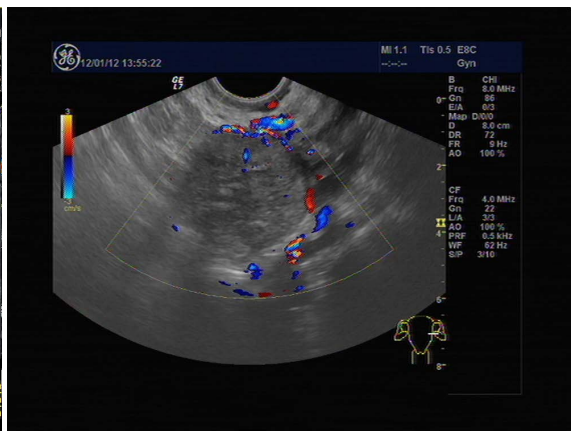

(D)

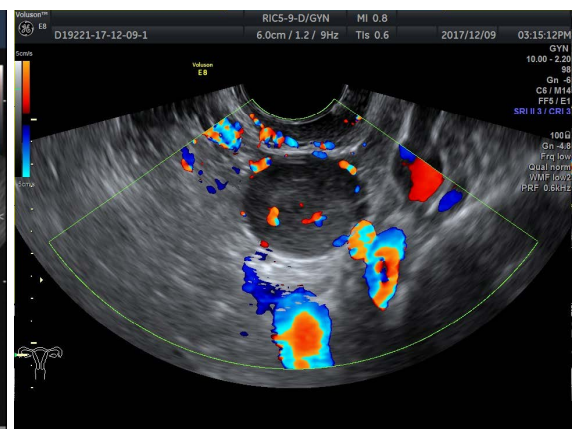

(F) 


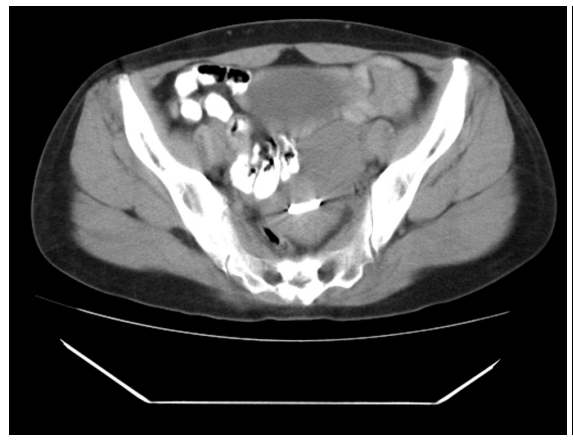

(G)

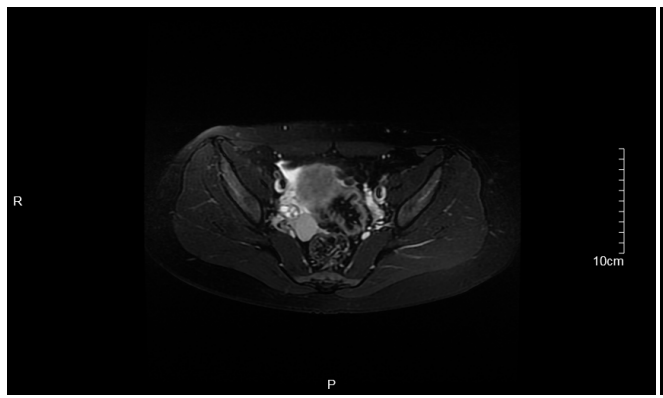

(I)

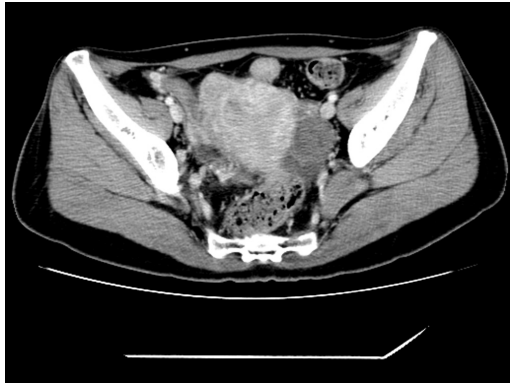

(K)

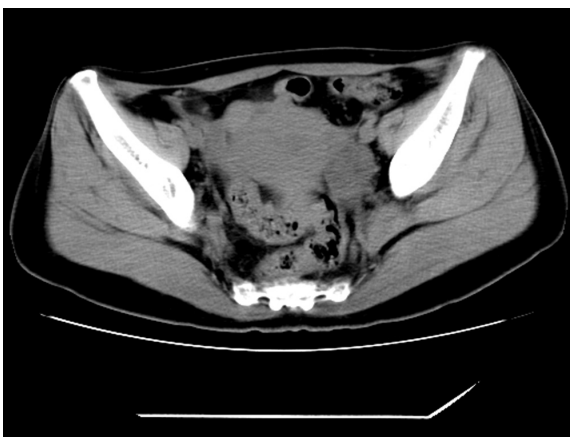

$(\mathrm{H})$

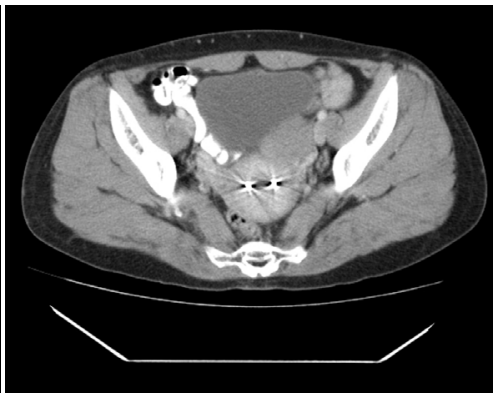

(J)

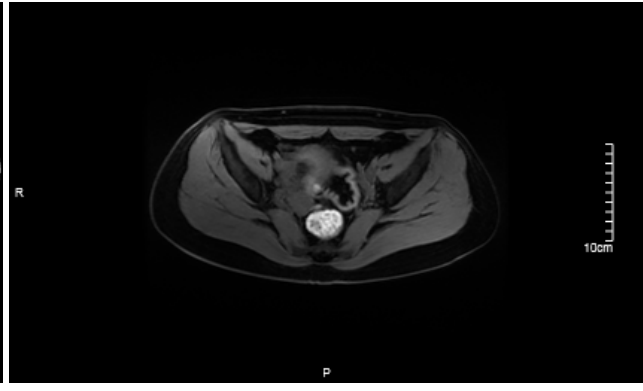

(L)

Figure 1. FATWOs in case 1 and case 2. (A) (B) Transvaginal sonographic images showed solid, well-demarcated masses (case 1: $4.0 \times 4.1 \times 4.8 \mathrm{~cm}^{3}$, case $2: 4.4 \times 3.8 \times 3.0$ $\mathrm{cm}^{3}$ ) beside the left ovary. FATWOs in case 3; (C) Transvaginal sonographic images showed solid, well-demarcated masses (case 3: $2.7 \times 2.0 \times 2.5 \mathrm{~cm}^{3}$ ) beside the right ovary. Closely packed small cysts in Case 2; (D) (E) (F) Color Doppler images showed moderate vascularization in the mass; $(\mathrm{G})(\mathrm{H}) \mathrm{CT}$ showed solid mass (case $1: 3.8 \times 4.3 \times 4.0 \mathrm{~cm}^{3}$ ) or cystic-solid mass (case 2: $3.3 \times 2.8 \times 3.5 \mathrm{~cm}^{3}$ ) in the left adnexal region; (I) MRI showed solid mass (case 3: $2.6 \times 2.0 \times 2.4 \mathrm{~cm}^{3}$ ) in the right adnexal region; $(\mathrm{J})(\mathrm{K})(\mathrm{L})$ Enhanced scans demonstrated moderately intensified mass.

right fallopian tube or broad ligament rather than with the right ovary because the adjacent ovary presented an intact and normal appearance. Moreover, it did not move when both ovary moved regularly with the abdominal respiration. In Case 1, the uterus was enlarged and had several hypo-echoic masses. The largest one measured $5.0 \times 5.0 \times 4.7 \mathrm{~cm}$ and located in the right-anterior wall. The other adnexus had no positive findings in three cases.

The computed tomography (CT) displayed a left adnexal mass measuring 3.8 $\times 4.3 \times 4.0 \mathrm{~cm}^{3}$ in Case 1 (Figure $1(\mathrm{G})$ ) and $3.3 \times 2.8 \times 3.5 \mathrm{~cm}^{3}$ and Case 2 
(Figure 1(H)). Magnetic Resonance Imaging (MRI) displayed a left adnexal mass measuring $2.6 \times 2.0 \times 2.4 \mathrm{~cm}^{3}$ in Case 3 (Figure $1(\mathrm{I})$ ), respectively. The inner wall of the cystic parts in the tumor of Case 2 was irregular. The 30HU CT value suggested that the fluid inside was viscous. Enhanced scan demonstrated that the solid parts including the cystic walls were moderately intensified (Figures $1(\mathrm{~J})-(\mathrm{L})$ ). No apparent enlarged pelvic and para-aortic lymph nodes were shown in three cases.

On gross section, three tumors were well circumscribed and encapsulated. They were located in both mesosalpinx. The both fallopian tube and ovary were normal. The tumors measured $5.0 \mathrm{~cm}$ (Case 1) and $4.0 \mathrm{~cm}$ (Case 2) and $3.0 \mathrm{~cm}$ (Case 3) in diameter. They presented predominantly solid except the presence of occasional small cysts in Case 2. The sectioned surface of three tumors was white or yellow and rubbery. No hemorrhage or necrosis was presented.

Microscopically, the tumors predominantly showed a diffuse solid pattern with occasional sieve-like cystic areas (Figure 2(A)). The solid area had a compact proliferation of ovoid cells reflecting closed tubes (Figure 2(B)). The cystic pattern was relatively common in Case 1, which closely resembles the retiform variant of Sertoli-Ledig cell tumor. The nuclei of these cells were round, and had fine chromatins and occasional nuclear indentations (Figure 2(C)). The cytoplasm was pale and inconspicuous. The mitotic figures were uncommon (1-2/10HPF). The fibrous stroma was absent. There was no necrosis or evidence of vascular invasion in three cases. Immunostaining showed a specific profile including positive staining of Inhibin, Calretinin, D2-40, WT1, AR, p53, CD10, CD99, and WT1, and negative staining of CK5/6, EMA, Vim and CD31 (Figures 2(D)-(F)). The Ki67 labeling index was less than $5 \%$.

\section{Discussion}

The term "female adnexal tumors of probable Wolffian origin (FATWOs)" was first described by Kariminejad and Scully in 1973. Evidences for its Wolffian origin have been subsequently provided by many other authors. They include the overlapping location with Wolffian remnants (the broad ligament), different ultrastructural features and morphologic deviation from any neoplasms arising from the Mullerian derivative or the surface epithelium of the ovary, and similar immunohistochemical phenotypes to that of Wolffian remnants [1].

These tumors lack specific symptoms and most of them were incidentally found. They are histopathologically indistinguishable from ovarian sex-cord tumors [2]. Fortunately, extra-ovarian sex-cord tumors are exceedingly rare and may be non-existed in fact. The precise anatomic site becomes the key point for differentiating between these two entities. Generally, FATWOs have a low malignant potential since some patients have shown evidence of recurrence. A pre-operative detailing on this disease, particularly that of imaging findings, becomes an important issue in clinical intervention for these patients. However, to the best of our knowledge, there are no reports that were focused on imaging features of FATWOs up to date. 


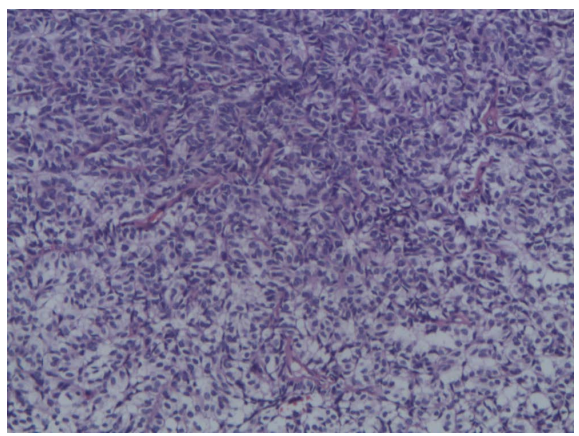

(A)

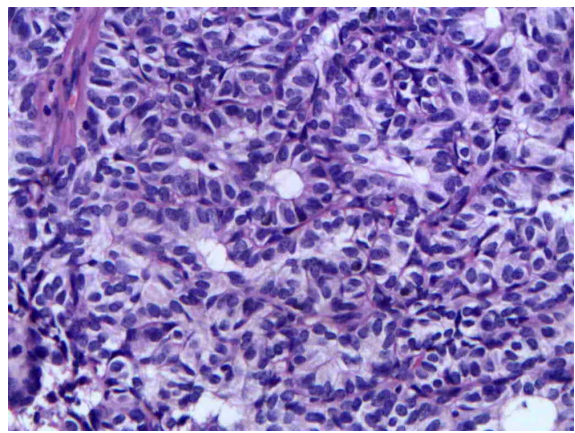

(C)

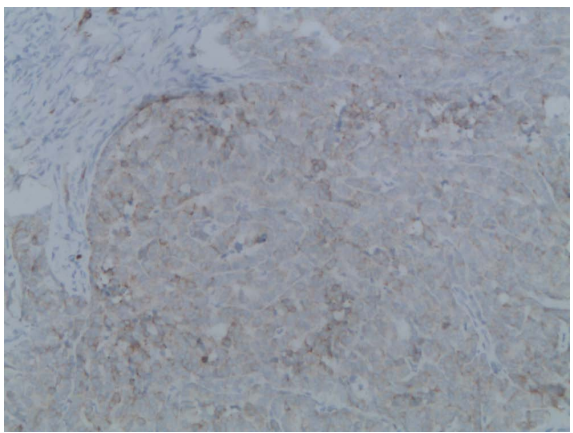

(E)

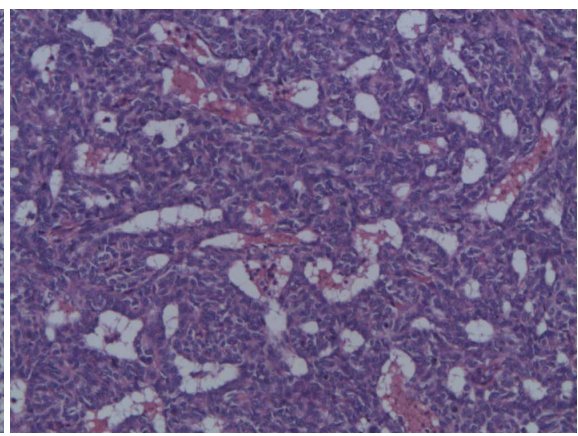

(B)

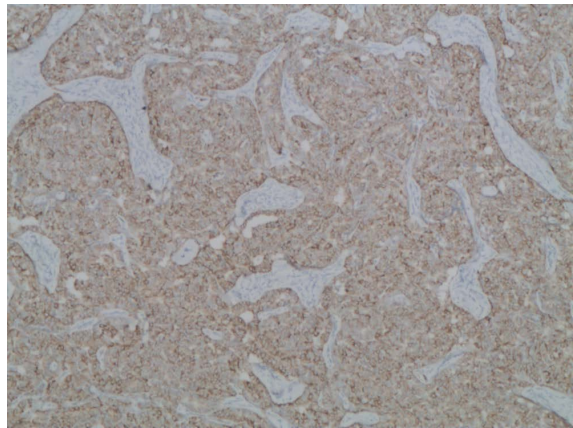

(D)

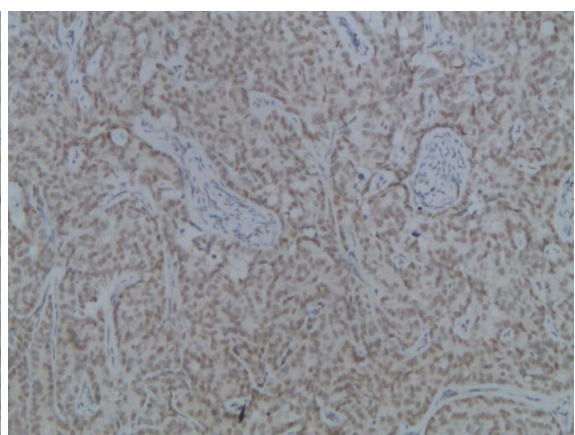

(F)

Figure 2. Histopathological features of FATWOs. (A) The characteristic solid pattern reflected the closed tubes $(\mathrm{HE} \times 5)$; (B) The open tubes $(\mathrm{HE} \times 5)$; (C) The nuclear features $(\mathrm{HE} \times 40)$; (D) (E) (F) The positive staining of cytokeratin, inhibin \& AR, respectively (immunostaining $\times 20$ ).

It is well established that FATWOs occur along the trajectory of the broad ligament, which extends from the hilum of the ovary to the outer third of the vagina $^{2}$. In 82 cases in previous reports [1]-[33] and the present three cases, the anatomic sites of tumor was located at mesosalpinx in 24 cases (left 6 , right 8 , unnoted lateral 10), broad ligament in 42 (left 6, right 11, unnoted lateral 25), hilum of ovary in 12 (paravagina 3 and pelvis 3). Hence, we believe that the anatomic location of the tumor in the area of broad ligament (mesosalpinx) may be a key clue for diagnosis of FATWOs. The following ultrasound features support the location of the tumor at mesosalpinx. Firstly, the ovaries are intact and present a clear-cut boundary with neighboring tumor; secondly, tumors do not move following ovary at the same side during the abdominal respiration. How- 
ever, such judgment of the exact relationship between the mass and the ovary sometimes may be difficult when the mass is too large. Under such circumstances, high-solution CT may be helpful for the diagnosis of FATWOs.

In three cases, a pelvic mass was incidentally found by ultrasound in her routine physical check-up. The literature reports that the tumor is mostly unilateral, and the right side is more common than the left side. Diagnosis depends on pathology. The three patients are still alive. Most authors believe that most FATWOs are benign lesions, but a few cases may have recurrence and metastasis, usually occurring between 2 and 8 years. Because the tumor is rare and the follow-up period is short, it is difficult to accurately judge.

We found that, in agreement with the gross morphology, three tumors were well demarcated, predominantly solid with areas of closely packed small cyst (Case 1), and had moderately color content at color Doppler examination. These features were common in Sertoli-Leydig cell tumors of ovary [34]. But Sertoli-Leydig cell tumor is never found within the trajectory of the broad ligament in clinical practice. FATWOs should be differentiated from other masses, particularly leiomyoma, in the broad ligament or surrounding regions by ultrasound. Sonographically, a leiomyoma typically has a whorled appearance with characteristic acoustic shadowing. Some leiomyomas have a rim of Doppler signals [35]. Leiomyomas with degenerative changes often lose the characteristic whirlpool structures and appear to be solid-cystic. However, these leiomyomas always show low color content at color Doppler examination. Moreover, the compact small cysts are very unusual in FATWOs.

\section{Conclusion}

In conclusion, an ultrasound finding presenting a predominant-solid well demarcated mass with moderate vascularization, probably with packed small cysts, in the broad ligament region (mesosalpinx) may provide a clue for preoperative diagnosis of FATWOs.

\section{Conflicts of Interest}

The authors declare no conflicts of interest regarding the publication of this paper.

\section{References}

[1] Steed, H., Oza, A., Chapman, W.B., Yaron, M. and Petrillo, D.D. (2009) Female Adnexal Tumor of Probable Wolffian Origin: A Clinicopathological Case Report and a Possible New Treatment. International Journal of Gynecologic Cancer, 14, 546-550. https://doi.org/10.1111/j.1048-891x.2004.014319.x

[2] Ramirez, P.T., Wolf, J.K., Malpica, A., Deavers, M.T., Liu, J. and Broaddus, R. (2002) Wolffian Duct Tumors: Case Reports and Review of the Literature. Gynecologic Oncology, 86, 225-230. https://doi.org/10.1006/gyno.2002.6739

[3] Semple, D., Kingston, R. and Farquharson, R. (1998) Female Adnexal Tumor of Probable Wolffian Origin. Journal of Obstetric and Gynaecology, 18, 200-201. 
https://doi.org/10.1080/01443619868109

[4] Melcher, L. and Gomez-Lobo, V. (2008) Diagnosis and Surgical Approach in Two Cases of Female Adnexal Tumors of Probable Wolffian Origin in Young Adolescents. Journal of Pediatric and Adolescent Gynecology, 21, 69. https://doi.org/10.1016/j.jpag.2008.01.018

[5] Tiltman, A.J. and Allard, U. (2001) Female Adnexal Tumor of Probable Wolffian Origin: An Immunohistochemical Study Comparing Tumors, Mesonephric Remnants and Paramesonephric Derivatives. Histopathology, 38, 237-242. https://doi.org/10.1046/j.1365-2559.2001.01086.x

[6] Rahilly, M.A., Williams, A.R.W., Krause, T. and Nafussi, A.A. (1995) Female Adnexal Tumor of Probable Wolffian Origin: A Clinicopathological and Immunohistochemical Study of Three Cases. Histopathology, 26, 69-74. https://doi.org/10.1111/j.1365-2559.1995.tb00623.x

[7] Kariminejad, M.H. and Scully, R.E. (1973) Female Adnexal Tumor of Probable Wolffian Origin a Distinctive Pathology Entity. Cancer, 31, 671-677. https://doi.org/10.1002/1097-0142(197303)31:3<671::AID-CNCR2820310328>3.0.C $\underline{\mathrm{O} ; 2-\mathrm{K}}$

[8] Delaloye, J.F., Ruzicka, J. and De Grandi, P. (1993) An Ovarian Tumor of Probable Wolffian Origin. Acta Obstetricia et Gynecologica Scandinavica, 72, 314-316. https://doi.org/10.3109/00016349309068045

[9] Devouassoux-Shisheboran, M., Silver, S.A. and Tavassoli, F.A. (1999) Wolffian Adnexal Tumor, So-Called Female Adnexal Tumor of Probable Wolffian Origin (FATWO): Immunohistochemical Evidence in Support of a Wolffian Origin. $\mathrm{Hu}$ man Pathology, 30, 856-863. https://doi.org/10.1016/S0046-8177(99)90148-X

[10] Harada, O., Ota, H., Takagi, K., Matsuura, H., Hidaka, E. and Nakayama, J. (2006) Female Adnexal Tumor of Probable Wolffian Origin: Morphological, Immunohistochemical, and Ultrastructural Study with c-Kit Gene Analysis. Pathology International, 56, 95-100. https://doi.org/10.1111/j.1440-1827.2006.01930.x

[11] Atallah, D., Rouzier, R., Voutsadakis, I., et al. (2004) Malignant Female Adnexal Tumor of Probable Wolffian Origin Relapsing after Pregnancy. Gynecologic Oncology, 96, 402-404. https://doi.org/10.1016/j.ygyno.2004.07.042

[12] Lesin, J., Forko-Ilic, J., Plavec, A. and Planinic, P. (2009) Management of Wolffian Duct Recurrence without Chemotherapy. Archives of Gynecology and Obstetrics, 280, 855-857. https://doi.org/10.1007/s00404-009-1024-1

[13] Matsuki, M., Kaji, Y. and Matsuo, M. (1999) Female Adnexal Tumor of Probable Wolffian Origin: MR Findings. The British Journal of Radiology, 72, 911-913. https://doi.org/10.1259/bjr.72.861.10645202

[14] Inoue, H., Kikuchi, Y., Hori, T., Nabuchi, K., Kobayashi, M. and Nagata, I. (1995) An Ovarian Tumor of Probable Wolffian Origin with Hormonal Function. Gynecologic Oncology, 59, 304-308. https://doi.org/10.1006/gyno.1995.0027

[15] Sato, T., Isonishi, S., Sasaki, K., et al. (2012) A Case of Female Adnexal Tumor of Probable Wolffian Origin: Significance of MRI Findings. International Cancer Conference Journal, 1, 108-112. https://doi.org/10.1007/s13691-012-0021-6

[16] Tamiolakis, D. and Anastasiadis, P. (2007) Metastatic Female Adnexal Tumor of Probable Wolffian Origin. A Histocytopathological Correlation. Cytopathology, 18, 264-266. https://doi.org/10.1111/j.1365-2303.2006.00364.x

[17] Bata, M.S. and Kamal, M.F. (1999) Female Adnexal Tumor of Probable Wolffian Origin in a 23-Year-Old Woman. European Journal of Obstetric \& Gynecology and 
Reproductive Biology, 87, 179-182. https://doi.org/10.1016/S0301-2115(99)00108-6

[18] Kim, K.J., Jeong, D.K., Jang, B.W., et al. (2002) Female Adnexal Tumor of Probable Wolffian Origin. Gynaecological Endoscopy, 11, 159-162. https://doi.org/10.1046/j.1365-2508.2002.00499.x

[19] Sivridis, E., Giatromanolaki, A., Koutlaki, N. and Anastasiadis, P. (2005) Malignant Female Adnexal Tumour of Probable Wolffian Origin: Criteria of Malignancy. Histopathology, 46, 716-718. https://doi.org/10.1111/j.1365-2559.2005.02035.x

[20] Deen, S., Duncan, T.J. and Hammond, R.H. (2007) Malignant Female Adnexal Tumor of Probable Wolffian Origin. International Journal of Gynecological Pathology, 26, 383-386. https://doi.org/10.1097/pgp.0b013e3180645136

[21] Flanagan, A.M., Kane, J.L. and Norman-Taylor, J.O. (1987) Female Adnexal Tumor of Probable Wolffian Origin. British Journal of Obstetrics and Gynaecology, 94, 270-272. https://doi.org/10.1111/j.1471-0528.1987.tb02367.x

[22] Brescia, R.J., Almeida, P.C.C.D., Fuller, A.F., Dickersin, G.R. and Robboy, S.J. (1985) Female Adnexal Tumor of Probable Wolffian Origin with Multiple Recurrence over 16 Years. Cancer, 56, 1456-1461.

https://doi.org/10.1002/1097-0142(19850915)56:6<1456::AID-CNCR2820560638>3. $\underline{0 . \mathrm{CO} ; 2-\mathrm{Z}}$

[23] Taxy, J.B. and Battifora, H. (1976) Female Adnexal Tumor of Probable Wolffian Origin Evidence for a Low Grade Malignancy. Cancer, 37, 2349-2354.

https://doi.org/10.1002/1097-0142(197605)37:5<2349::AID-CNCR2820370526>3.0. $\mathrm{CO} ; 2-\mathrm{X}$

[24] Xu, T., Chang, W. and Cui, M. (2012) Tumor of the Mesosalpinx: Case Report of a Female Adnexal Tumor of Probable Wolffian Origin. European Journal of Gynaecological Oncology, 33, 233-235.

[25] Syriac, S., Durie, N. and Kesterson, J. (2011) Female Adnexal Tumor of Probable Wolffian Origin (FATWO) with Recurrence 3 Years Postsurgery. International Journal of Gynecological Pathology, 30, 231-235. https://doi.org/10.1097/PGP.0b013e3182005340

[26] Veenu, J., Tarun, A. and Veena, S. (2007) Female Adnexal Tumor of Probable Wolffian Origin. Indian Journal of Pathology \& Microbiology, 50, 806-808.

[27] Daya, D., Murphy, J. and Simon, G. (1994) Paravaginal Female Adnexal Tumor of Probable Wolffian Origin. American Journal of Clinical Pathology, 101, 275-278. https://doi.org/10.1093/ajcp/101.3.275

[28] Daya, D. (1994) Malignant Female Adnexal Tumor of Probable Wolffian Origin with Review of the Literature. Archives of Pathology \& Laboratory Medicine, 118, 310-312.

[29] Li, C.C., Qian, Z.R., Hirokawa, M., et al. (2004) Expression of Adhesion Molecules and Ki-67 in Female Adnexal Tumor of Probable Wolffian Origin (FATWO): Report of Two Cases and Review of the Literature. APMIS, 112, 390-398.

[30] Sheyn, I., Mira, J.L., Bejarano, P.A. and Husseinzadeh, N. (2000) Metastatic Female Adnexal Tumor of Probable Wolffian Origin: A Case Report and Review of the Literature. Archives of Pathology \& Laboratory Medicine, 124, 431-434.

[31] Wagatsuma, S., Yaegashi, N., Namiki, T., Sato, S. and Yajima, A. (1997) A Case of Female Adnexal Tumor of Probable Wolffian Origin: Histologically, Tumor Cells Showed Three Different Patterns. The Tohoku Journal of Experimental Medicine, 181, 371-377. https://doi.org/10.1620/tjem.181.371

[32] Rorat, E. and Wallach, R.C. (1983) Clinical Outcome for the Female Adnexal Tu- 
mor of Probable Wolffian Origin. International Journal of Gynecology \& Obstetrics, 21, 409-412. https://doi.org/10.1016/0020-7292(83)90009-7

[33] Shirley, S.E. and Coard, K.C. (1999) Female Adnexal Tumour of Probable Wolffian Origin. The West Indian Medical Journal, 48, 244-245.

[34] Demidov, V.N., Lipatenkova, J., Vikhareva, O., Holsbek, C.V., Timmerman, D. and Valentin, L. (2008) Imaging of Gyenecological Disease (2): Clinical and Ultrasound Characteristics of Sertoli Cell Tumors, Sertoli-Leydig Cell Tumors and Leydig Tumors. Ultrasound in Obstetrics \& Gynecology, 31, 85-91. https://doi.org/10.1002/uog.5227

[35] Pelsang, R.E., Sorosky, J. and Wodds, T. (1999) Sonographic Evaluation of a Leiomyoma of the Broad Ligament of the Uterus. Journal of Clinical Ultrasound, 27, 402-404.

https://doi.org/10.1002/(SICI)1097-0096(199909)27:7<402::AID-JCU7>3.0.CO;2-W 